\title{
Structural Mechanism Underlying Ligand Binding and Activation of PPARY
}

\author{
Jinsai Shang ${ }^{1,3}$ and Douglas J. Kojetin ${ }^{1,2, *}$ \\ ${ }^{1}$ Department of Integrative Structural and Computational Biology, The Scripps Research Institute, Jupiter, FL, 33458, USA \\ ${ }^{2}$ Department of Molecular Medicine, The Scripps Research Institute, Jupiter, Florida 33458, USA \\ ${ }^{3}$ Current address: Bioland Laboratory (Guangzhou Regenerative Medicine and Health Guangdong Laboratory), Guangzhou 510700, China \\ * Correspondence: dkojetin@scripps.edu
}

\begin{abstract}
Ligands bind to an occluded orthosteric pocket within the nuclear receptor (NR) ligand-binding domain (LBD). Molecular simulations have revealed several theoretical ligand entry/exit pathways to the orthosteric pocket, but experimentally it remains unclear whether ligand binding proceeds through induced fit or conformational selection mechanisms. Using NMR spectroscopy lineshape analysis, we show that ligand binding to the peroxisome proliferator-activated receptor gamma (PPARY) LBD involves a two-step induced fit mechanism including an initial fast step followed by slow conformational change. Surface plasmon resonance and isothermal titration calorimetry heat capacity analysis support the fast kinetic binding step and the conformational change after binding step, respectively. The putative initial ligand binding pose is suggested in several crystal structures of PPARy LBD where a ligand is bound to a surface pore formed by helix 3 , the $\beta$-sheet, and the $\Omega$-loop-one of several ligand entry sites suggested in previous targeted and unbiased molecular simulations. These findings, when considered with a recent NMR study showing the activation function-2 (AF-2) helix 12 exchanges in and out of the orthosteric pocket in apo/ligand-free PPARy, suggest an activation mechanism whereby agonist binding occurs through an initial encounter complex with the LBD followed by transition of the ligand into the orthosteric pocket concomitant with a conformational change resulting in a solvent-exposed active helix 12 conformation.
\end{abstract}

\section{INTRODUCTION}

Nuclear receptors (NRs) comprise a superfamily of transcription factors that evolved to bind and functionally respond to endogenous small molecule ligands (1). NRs contain a conserved domain organization including a central DNA-binding domain flanked by two regulatory regions, a disordered N-terminal activation function-1 (AF-1) domain and a C-terminal ligand-binding domain (LBD) containing the activation function-2 (AF2) coregulator interaction surface. Endogenous and synthetic ligands bind to an orthosteric pocket within the core of the NR LBD. Ligand binding affects the conformation of the AF-2 surface and changes the binding affinity for chromatin remodeling transcriptional coregulator proteins resulting in activation or repression of gene transcription $(2,3)$.

Crystal structures have defined static active and inactive/repressive conformations of NR LBDs bound to ligands that enable binding of transcriptional coactivator and corepressor proteins, respectively, by stabilizing specific conformations of the AF-2 helix 12 (4). However, mechanistically it remains poorly understood how ligands engage the LBD and enter the orthosteric ligand-binding pocket-whether ligand binding occurs through conformational selection or induced fit mechanisms (5). In the conformational selection scenario, ligand binding selectively binds to and selects a particular conformation that is populated within the dynamic LBD conformational ensemble. In the induced fit scenario, ligand binding occurs through an encounter complex and induces or pushes the LBD conformational ensemble into the final ligand-bound complex.

In NR LBD crystal structures, ligands bound orthosteric pockets are occluded from solvent suggesting an induced fit binding mechanism. A recent review of molecular simulations on various NR LBDs identified six potential locations involved in ligand entry and exit pathways to the NR orthosteric pocket (6). Most molecular simulation studies focused on ligand egress or unbinding from the orthosteric pocket. However, coarse grained simulations on farnesoid X receptor (FXR) suggest ligand binding occurs through induced fit mechanism (7) via an orthosteric pocket entry site that was also observed in simulations of peroxisome proliferator-activated receptor gamma (PPAR $\gamma)$ (8). Molecular simulations of ligand binding to steroid receptors including androgen receptor (AR), estrogen receptor alpha $(E R \alpha)$, glucocorticoid receptor (GR), mineralocorticoid receptor (MR), and progesterone receptor $(\mathrm{PR})$ also suggest an induced fit mechanism $(9,10)$, although the site of ligand entry into the orthosteric pocket is different than FXR (7) and PPAR $\gamma$ (8). Indeed, ligand binding to nuclear receptors is often described to induce an active conformation (4, 11-16). However, there is evidence from NMR studies on PPAR $\gamma$ that in the absence of ligand the apo-LBD exchanges between transcriptionally active and transcriptionally inactive/repressive conformations (17) suggesting a role for conformational selection in the ligand binding mechanism of NR agonists, which are thought to stabilize an active conformation from a dynamic ensemble of active and inactive/repressive conformations $(15,18-27)$. Taken together, these observations stem from the ability of the ligand-bound NR LBD to exert specific functions such as coactivator interaction and transcription, but not directly on the mechanism of ligand binding to the orthosteric pocket.

Here, we use protein NMR lineshape analysis, which provides atomic resolution structural insight into conformational selection and induced fit binding mechanisms (28), to study the mechanism of agonist binding to PPAR $\gamma$. We find that agonist binding to the PPAR $\gamma$ LBD occurs through an induced fit mechanism with two steps, an initial fast kinetic step followed by a slow conformational change step, which we independently confirm using surface plasmon resonance (SPR) and temperature-dependent isothermal titration calorimetry (ITC) heat capacity analysis, respectively. Crystal structures show that ligands can bind to a surface pore in the PPAR $\gamma \mathrm{LBD}$, a site implicated as a putative ligand entry site in molecular simulations. We discuss the implication of our findings within the context of our recent NMR study showing that helix 12 occupies the orthosteric ligand-binding pocket in apo-PPAR $\gamma$ (17) that when taken together describes a more complete mechanism by which agonist binding induces activation of PPAR $\gamma$.

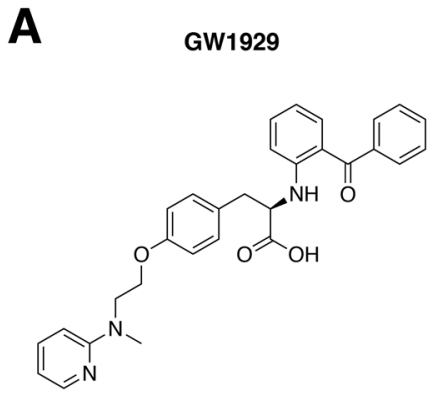

B ligand displacement

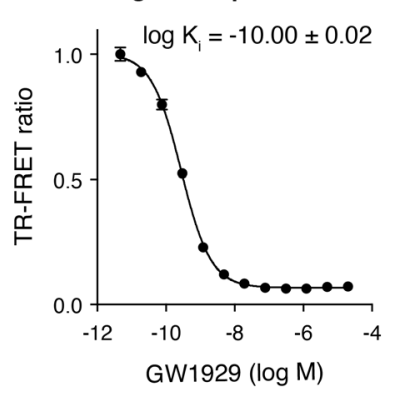

Fig. 1. Affinity characterization of GW1929. (A) Chemical structure of GW1929. (B) TR-FRET fluorescent tracer ligand displacement assay measuring the inhibition constant $\left(\mathrm{K}_{\mathrm{i}}\right)$ of GW1929 binding to the PPARY LBD.. 
bioRxiv preprint doi: https://doi.org/10.1101/2020.09.22.298109; this version posted September 22, 2020. The copyright holder for this preprint (which was not certified by peer review) is the author/funder, who has granted bioRxiv a license to display the preprint in perpetuity. It is made available under aCC-BY 4.0 International license.

\section{RESULTS}

\section{NMR lineshape analysis of agonist binding}

To study the mechanism of ligand binding to PPAR $\gamma$, we used a previously reported high affinity synthetic PPAR $\gamma$ agonist called GW 1929 (Fig. 1A) (29) that displays a $100 \mathrm{pM}$ inhibitory binding constant $\left(\mathrm{K}_{\mathrm{i}}\right)$ (Fig. 1B). We collected $2 \mathrm{D}\left[{ }^{1} \mathrm{H}-{ }^{15} \mathrm{~N}\right]-\mathrm{TROSY}-\mathrm{HSQC}$ NMR spectra of ${ }^{15} \mathrm{~N}$-PPAR $\gamma$ LBD in the absence and presence of increasing substoichiometric molar concentrations of GW 1929 (Fig. S1). For a simple two-state ligand binding mechanism, also called a "lock-and-key" or U model (28), titration of a high affinity ligand with mid-picomolar affinity in principle should result in NMR chemical shift perturbations that occur in slow exchange on the NMR time scale. The intensity of the ligand-free/apo-protein signal would be expected to decrease during the titration while the ligand-bound/holo-protein signal increases. By comparison, titration of a low affinity ligand should cause chemical shift perturbations that occur in fast exchange, causing the apo-protein signal to shift towards the holo-protein signal.

During the GW 1929 titration, a mixture of fast and slow exchange NMR lineshapes occur (Fig. 2A) for residues dispersed throughout the PPAR $\gamma$ LBD (Fig. 2B). The ligand-free apo-peaks disappear in fast exchange, and the ligand-bound holo-peaks are populated in slow exchange. The mixture of fast and slow exchange indicates that GW 1929 binding to PPAR $\gamma$ LBD occurs via a threestate mechanism (28) where the protein either isomerizes between two conformations (U-R and U-RL models) or undergoes monomer-dimer equilibrium in the absence or presence of ligand (U-R2 or U-R2L2). Small-angle X-ray scattering (SAXS), dynamic light scattering (DLS), size exclusion chromatography (SEC), and NMR data show that the apo- and ligand-bound PPAR $\gamma$ LBD is monomeric $(18,30)$, ruling out a potential contribution from protein dimerization (U-R2 and U-R2L2). Furthermore, GW1929 does not contain a racemizable chiral center that would result in an enantiomeric ligand isomerization mixture (U-L) and it is not likely that GW 1929 forms a dimer (U-L2), although these features would not contribute to the three-state protein-observed exchange mechanism (28). This leaves two protein isomerization scenarios that show a combination of fast and slow exchange components: ligand binding that occurs via conformational selection or induced fit. In the conformational selection scenario, the protein undergoes slow isomerization and the ligand binds with fast kinetics to a sparsely populated conformation, causing the apo-peak to disappear in slow exchange and the appearance of a holo-peak in fast exchange; this is opposite of what we see in the GW1929 titration data. However, these data are consistent with an induced fit scenario (Fig. 2C) where the ligand binds to the protein via a fast kinetic initial step that causes the apo-peak to disappear in fast exchange, which is followed by a slow step where the initial ligand-protein complex changes conformation into a more tightly bound conformation that causes the holo-peak to appear in slow exchange.
A
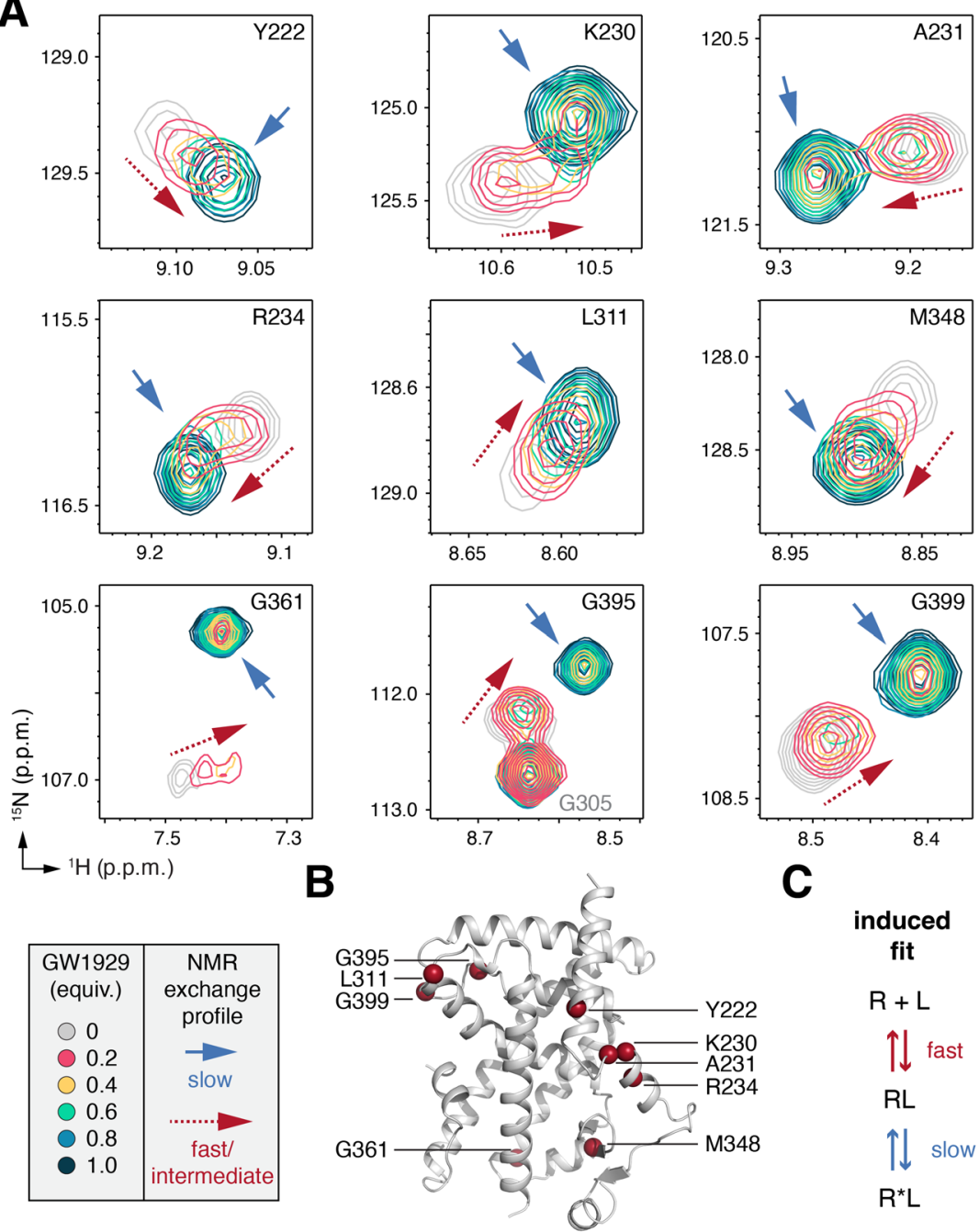

C
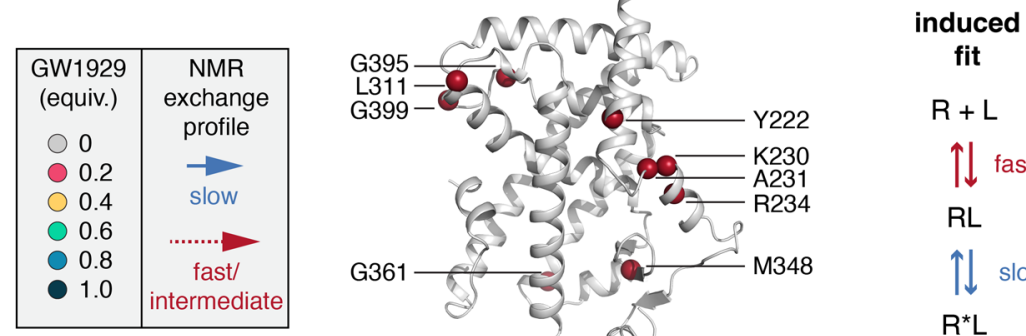

$\mathrm{R}+\mathrm{L}$

$\uparrow \downarrow$ fast

$\mathrm{RL}$

$\uparrow$ slow

$R^{\star} \mathrm{L}$

Fig. 2. NMR analysis of GW1929 binding to PPARY LBD. (A) Snapshots of $2 \mathrm{D}\left[{ }^{1} \mathrm{H},{ }^{15} \mathrm{~N}\right]-\mathrm{TROSY}-\mathrm{HSQC}$ NMR spectra of ${ }^{15} \mathrm{~N}$-labeled PPARy LBD in the absence or presence of increasing concentrations of GW1929. (B) Structural locations of the residues highlighted in the NMR analysis shown in A. (C) A two-state induced fit binding model that explains the mixture of fast and slow exchange lineshapes in the NMR titration data.
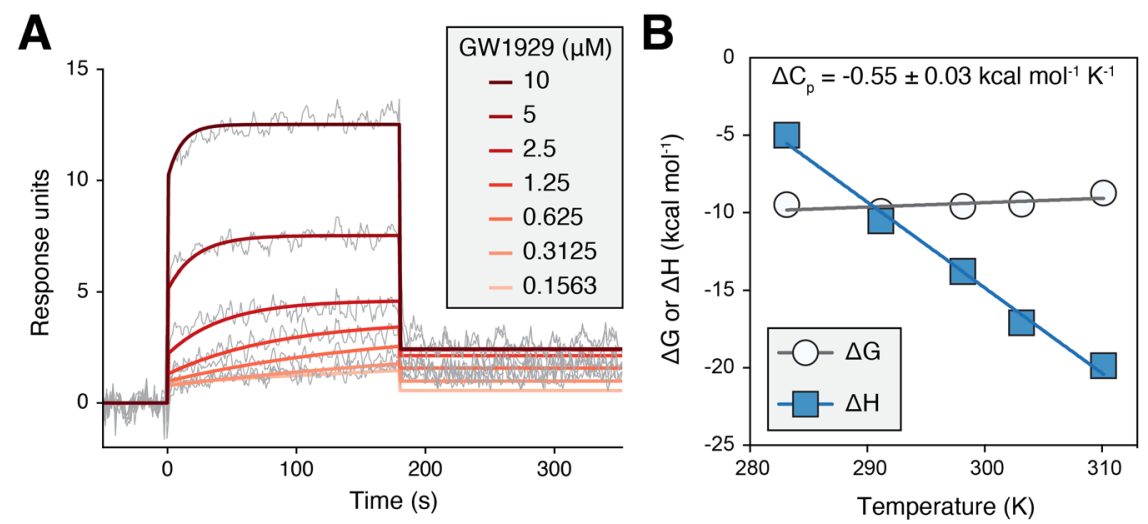

Fig. 3. SPR and ITC analysis of GW1929 binding. (A) SPR analysis of GW1929 binding to PPARy LBD shows fast kinetics. (B) Heat capacity $\left(\Delta C_{p}\right)$ analysis from temperature-dependent ITC titrations of GW1929 into PPARY LBD.

\section{SPR and ITC confirm fast and slow kinetic binding steps}

The induced fit binding mechanism suggested by the NMR titration data indicates that the initial ligand binding step involves fast kinetics. To confirm this observation, we performed surface plasmon resonance (SPR) 
bioRxiv preprint doi: https://doi.org/10.1101/2020.09.22.298109; this version posted September 22, 2020. The copyright holder for this preprint (which was not certified by peer review) is the author/funder, who has granted bioRxiv a license to display the preprint in perpetuity. It is made available under aCC-BY 4.0 International license.

experiments to monitor the binding kinetics of GW1929 to the PPAR $\gamma$ LBD (Fig. 3A). As anticipated from the NMR studies, the SPR sensorgram profiles show that GW1929 binds with a fast rate of binding $\left(\mathrm{K}_{\text {on }}\right.$ or $\mathrm{K}_{\mathrm{a}}$ ). Other published SPR studies of various structurally distinct synthetic PPAR $\gamma$ ligands similarly show fast kinetic rates of binding to the PPAR $\gamma$ LBD (31-42), suggesting that a fast initial binding step may be a common mechanism of ligand binding to the PPAR $\gamma$.

To confirm the slow conformational change step that occurs after the initial fast binding step revealed by the NMR studies, we performed isothermal titration calorimetry (ITC) experiments measuring the thermodynamic parameters of GW1929 binding to PPAR $\gamma$ LBD at several temperatures (Fig. S2). The magnitude and temperature dependence of the apparent binding heat capacity $\left(\Delta \mathrm{C}_{\mathrm{p}}\right)$, which is determined from the slope of the apparent binding enthalpy $(\Delta \mathrm{H})$ vs. temperature plot, informs whether binding occurs through a lock-and-key (small magnitude, temperature-independent $\Delta \mathrm{C}_{\mathrm{p}}$ ), conformational selection (larger magnitude, temperature-dependent $\Delta \mathrm{C}_{\mathrm{p}}$ ), or induced fit (larger magnitude, temperature-independent $\Delta \mathrm{C}_{\mathrm{p}}$ ) mechanism (43). GW 1929 binding to PPAR $\gamma$ LBD shows a strong linear coupling between $\Delta \mathrm{H}$ vs. temperature (Fig. $3 \mathbf{B}$ ), or a temperature-independent $\Delta \mathrm{Cp}$, indicative of an induced fit binding mechanism. Taken together, the SPR and ITC data provide support to the NMR data that show GW 1929 binds to PPAR $\gamma$ via a two-step induced fit mechanism that includes a fast initial kinetic binding step followed by a slow conformational change.

\section{Crystal structures reveal the putative ligand entry site to the orthosteric pocket}

A common method for obtaining ligand-bound crystal structures of PPAR $\gamma$ LBD is to grow apo-protein crystals and then perform a ligand soak to obtain the ligand-bound complex (44). This procedure is premised on the idea that the path of ligand entry into the orthosteric pocket is accessible to solvent channels within the crystal lattice. To visualize the putative ligand entry site, we grew crystals of apo-PPAR $\gamma$ LBD and solved the structure at $2.27 \AA$ (Table S1). Two chains are present in the asymmetric unit (Fig. S3) with different helix 12 conformations that are stabilized by a crystal artifact. Helix 12 in the chain A molecule adopts an active conformation and helix 12 in a chain $\mathrm{B}$ adopts a non-active conformation because it interacts with the AF-2 surface of a symmetry related chain A molecule. The structure reveals a putative orthosteric pocket entry site: a solvent accessible pore is formed by a surface consisting of helix 3 , the $\beta$-sheet, and the $\Omega$-loop (Fig. 4A). This region was also suggested by molecular dynamics simulations as a putative ligand entry and exit site to the occluded orthosteric ligand-binding pocket in the $\operatorname{PPAR} \gamma \operatorname{LBD}(8,45)$.

We soaked GW1929 into preformed apo-PPAR $\gamma$ LBD crystals and solved the structure to $2.07 \AA$ (Table S1). In chain A where helix 12 is stabilized in an active conformation, GW1929 adopts a binding mode within the orthosteric ligand-binding pocket as typical of PPAR $\gamma$ agonists (Fig. 4B). However, in chain B where helix 12 adopts a crystal contact-induced non-active helix 12 conformation, GW 1929 bound to the putative orthosteric pocket entry site. Other ligand-bound PPAR $\gamma$ LBD crystal structures obtained from soaking ligand into apo-protein crystals have similarly revealed a ligand bound to this pocket entrance in chain B molecules (Fig. S4) (24, 37, 46-51), including a crystal structure we previously solved of darglitazone-bound PPAR $\gamma$ LBD (Fig. 4C). These crystallography observations provide support that this solvent accessible pore at the helix $3 / \beta$-sheet $/ \Omega$-loop surface constitutes the ligand entry site to the PPAR $\gamma$ orthosteric pocket.

\section{Induced fit as a general PPARy ligand binding mechanism}

The data above raise a question as to whether other structurally distinct synthetic PPAR $\gamma$ agonists bind using an induced fit mechanism. To address
A
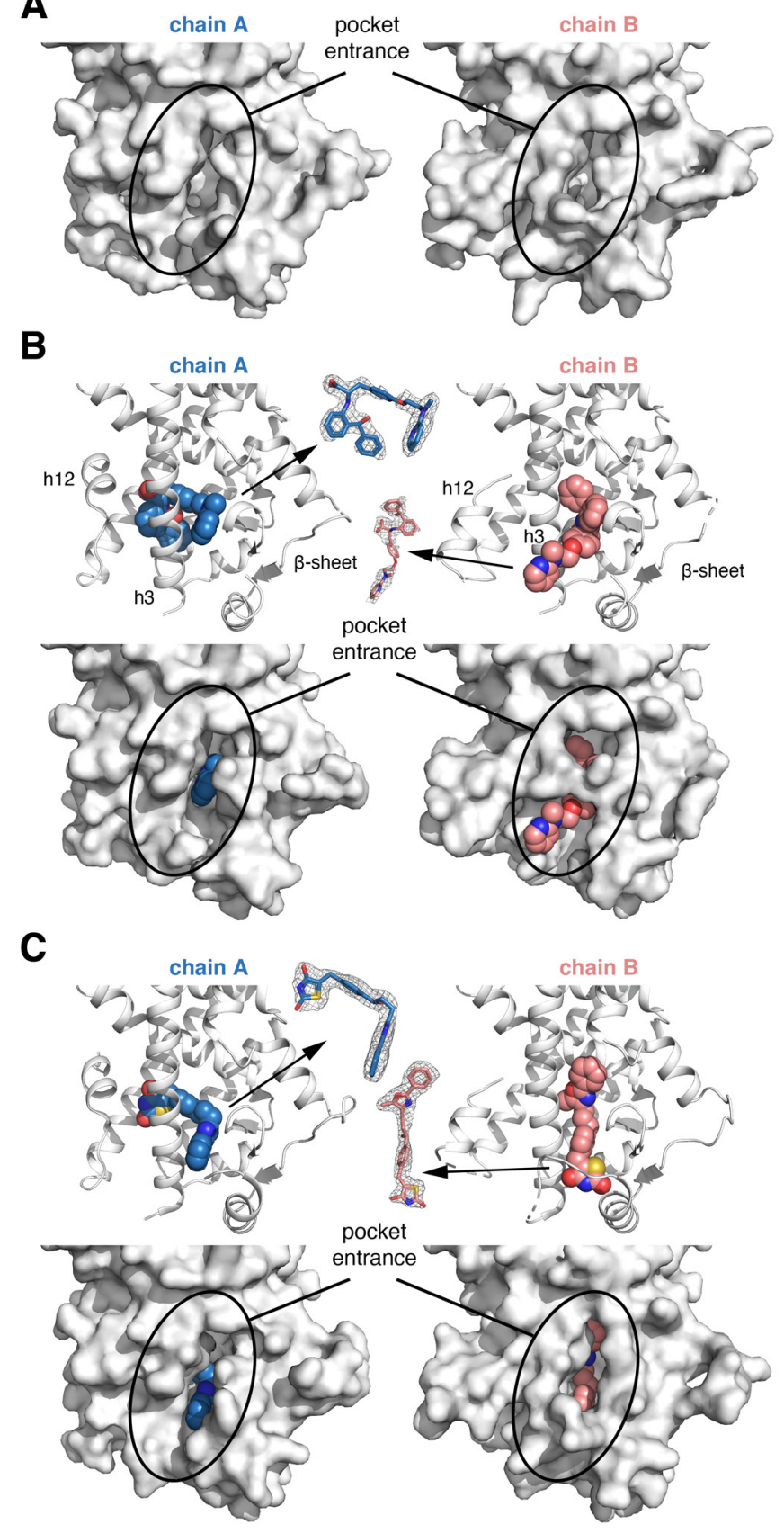

Fig. 4. Ligand soaking into apo-PPARy LBD crystals reveals an orthosteric pocket ligand entry pathway. (A) Crystal structure of apo-PPARY LBD reveals a surface pocket with access to the orthosteric ligand-binding pocket. (B,C) Soaking of GW1929 (B) or darglitazone (C) into preformed apo-PPARy LBD crystals reveals two ligand binding poses, one within the orthosteric pocket in chain A (blue ligand) and a second at the orthosteric pocket ligand entry site (pink ligand). Insets show ligand 2 Fo-Fc maps contoured at $1 \sigma$, and key structural elements are labeled.

this we used NMR to study the binding mechanism of a different full agonist, darglitazone, and a partial agonist, MRL24 (Fig. 5A), which display $\mathrm{K}_{\mathrm{i}}$ values at or below $1 \mathrm{nM}$ in a ligand displacement assay (Fig. 5B). We collected 2D $\left[{ }^{1} \mathrm{H}-{ }^{15} \mathrm{~N}\right]$-TROSY-HSQC NMR spectra of ${ }^{15} \mathrm{~N}$-PPAR $\gamma$ LBD in the absence and presence of substoichiometric molar concentrations of the high affinity agonists. Similar to the NMR titration of GW1929, we observed a mixture of fast and slow exchange NMR lineshapes upon titration of darglitazone (Fig. 5C, Fig. S5) and MRL24 (Fig. 5C, Fig. S6) associated with the disappearance of ligand-free apo-peaks (fast exchange) and appearance of ligand-bound holo-peaks (slow exchange). Taken to- 
A
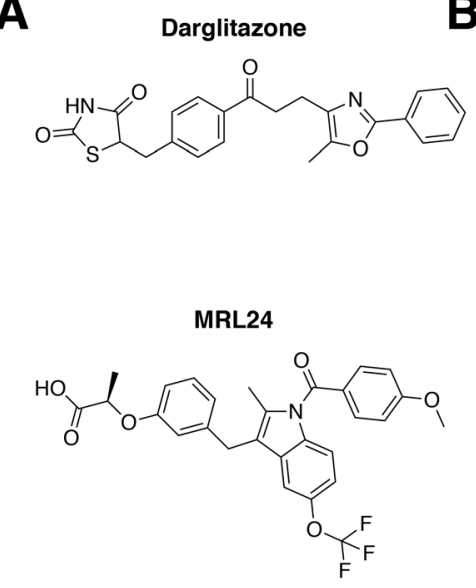

B

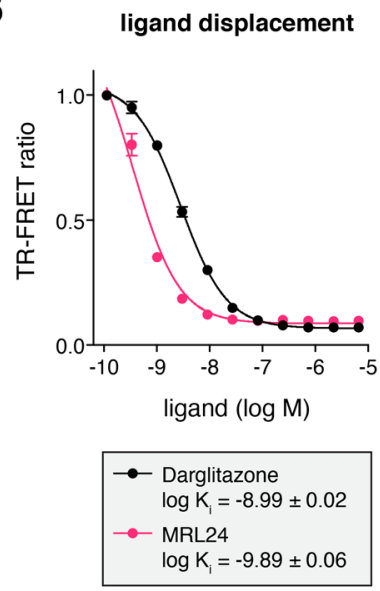

C

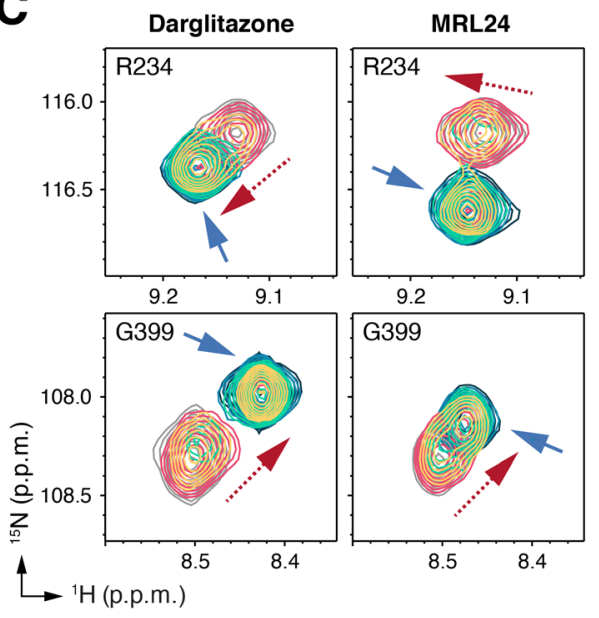

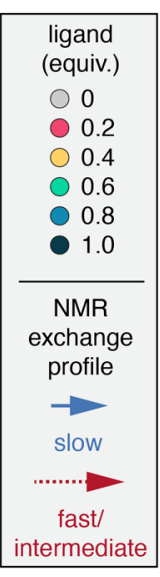

intermediate

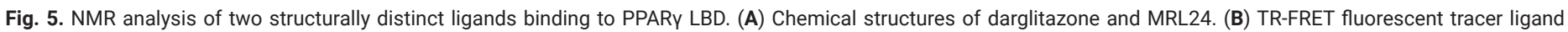

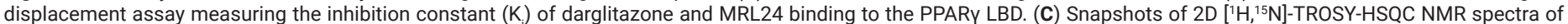
${ }^{15} \mathrm{~N}$-labeled PPARY LBD in the absence or presence of increasing concentrations of darglitazone or MRL24.

gether with the GW1929 studies, these data indicate that the induced fit binding mechanism may be a general ligand binding mechanism that is not an artifact associated with any one specific PPAR $\gamma$ ligand scaffold.

\section{A helix 12 mutant impairs full agonist-induced function but not binding mechanism}

When bound to the orthosteric pocket, full agonists such as darglitazone and GW1929 form a hydrogen bond with the side chain hydroxyl group of residue Y473 on helix 12. This tyrosine residue is thought to be critical for binding affinity and transcriptional efficacy of full agonists, but not partial agonists that do not interact with Y473 and display lower levels of PPAR $\gamma$-mediated transcription (52). The crystal structures of wild-type PPAR $\gamma$ LBD with the non-active helix 12 conformation observed in chain $\mathrm{B}$ provide one glimpse into a ligand encounter complex when helix 12 does not adopt an active conformation that points the Y473 side chain into the orthosteric pocket. To further determine how Y473 impacts the binding mechanism of darglitazone and GW1929, we generated a mutant [Y473E]-PPAR $\gamma$ LBD construct that we hypothesized would impact the ligand binding model in both chains A and B. In a TR-FRET coregulator interaction assay, the Y473E mutation significantly decreases the darglitazone $\mathrm{EC}_{50}$ and efficacy for increasing interaction of the TRAP220/MED1 coactivator peptide, and GW1929 shows essentially no concentration-dependent effect on the interaction (Fig. 6A).

We crystallized [Y473E]-PPAR $\gamma$ LBD under the same conditions used to generate apo-PPAR $\gamma$ LBD crystals and solved the structure at $2.30 \AA$ (Table S1). Overall, the [Y473E]-PPAR $\gamma$ LBD structure is highly similar to the apo-PPAR $\gamma$ LBD structure; chain A and B in both structures adopt an active and inactive conformation with $\mathrm{C} \alpha$ R.M.S.D values of $0.36 \AA$ and $0.40 \AA$ to the wild-type chain A and B conformers, respectively. We also solved structures after soaking darglitazone (Fig. 6B) and GW1929 (Fig. 6C) into preformed [Y473E]-PPAR $\gamma$ LBD crystals to $2.40 \AA$ and $2.15 \AA$ (Table S1), respectively. Ligand density is present at the ligand entry site but not in the orthosteric pocket in both chain A and B, indicating the Y473 side chain may be necessary for transition of the ligands into the final high affinity orthosteric binding pose within the crystals.

Although the TR-FRET and crystallography data indicate that the Y473E mutant inhibits or weakens GW1929 and darglitazone binding to the orthosteric pocket, 2D $\left[{ }^{1} \mathrm{H}-{ }^{15} \mathrm{~N}\right]$-TROSY-HSQC NMR spectra of ${ }^{15} \mathrm{~N}$-[Y473E]-PPAR $\gamma$ LBD titrated with substoichiometric molar concentrations of darglitazone (Fig. S7) and GW1929 (Fig. S8) reveals the ligands indeed bind to [Y473E]-PPAR $\gamma$ LBD. Moreover, NMR lineshape analysis of the titration series shows a mixture of fast and slow exchange indicating that binding of darglitazone and GW1929 (Fig. 6D) proceeds through an induced fit mechanism to [Y473E]-PPAR $\gamma$ LBD similar to the binding mechanism to wild-type PPAR $\gamma$ LBD. The slow exchange characteristic of the NMR titration profile suggests that the ligands bind to [Y473E]PPAR $\gamma$ LBD with a reasonably high affinity, which we confirmed for GW1929 using ITC (Fig. S9). Overlay of NMR spectra of wild-type or Y473E mutant ${ }^{15} \mathrm{~N}-\mathrm{PPAR} \gamma$ LBD bound to 1 equivalent of darglitazone (Fig. S10) or GW1929 (Fig. S11) look very similar with two notable exceptions. First, NMR peaks corresponding to residues in the AF-2 surface, in particular helix 12 but also helix 3-5 and other nearby structural elements, are present in wild-type spectra but missing in the Y473E mutant spectra due to dynamics on the $\mu$ s-ms intermediate exchange NMR time scale. Second, NMR peaks corresponding to residues within or nearby the AF-2 surface display chemical shift perturbations, likely due to the fact that helix 12 is dynamic and samples multiple conformations in the Y473E mutant but in wild-type PPAR $\gamma$ LBD it is stabilized in an active conformation via hydrogen bond formation between the ligand and the Y473 hydroxyl group.

Taken together, the Y473E ligand binding data are consistent with a dynamic activation model (3) whereby PPAR $\gamma$ agonism is associated with ligand-induced stabilization of helix 12, which is dynamic on the $\mu s-\mathrm{ms}$ time scale in apo-PPAR $\gamma(18,23-25)$. The NMR data indicate that darglitazone and GW 1929 binding to [Y473E]-PPAR $\gamma$ LBD stabilizes the dynamics of most of the orthosteric ligand-binding pocket, likely by binding to the orthosteric pocket in solution though not in the crystallized form. However, because the ligands do not hydrogen bond to the side chain of Y473E, helix 12 remains dynamic, which could explain the relatively flat ligand dose response curve in the TR-FRET assay despite their ability to bind with relatively high affinity. It is also possible that the addition of a coactivator peptide forces the [Y473E]-PPAR $\gamma$ LBD into an active AF-2 helix 12 conformation resulting in a clash between the glutamic acid side chain and the acid headgroup of GW1929 in the orthosteric binding pose. An electrostatic clash in the [Y473E]-PPAR $\gamma$ LBD crystals, or lack of the Y473 side chain in chain B of wild-type PPAR $\gamma$ crystals, could also explain why the ligands do not crystallize with an orthosteric binding pose. However, the NMR and ITC data indicate that the Y473E mutant does not prevent the ligands from binding to the orthosteric pocket in solution with high affinity. 
bioRxiv preprint doi: https://doi.org/10.1101/2020.09.22.298109; this version posted September 22, 2020. The copyright holder for this preprint (which was not certified by peer review) is the author/funder, who has granted bioRxiv a license to display the preprint in perpetuity. It is made available under aCC-BY 4.0 International license.

A

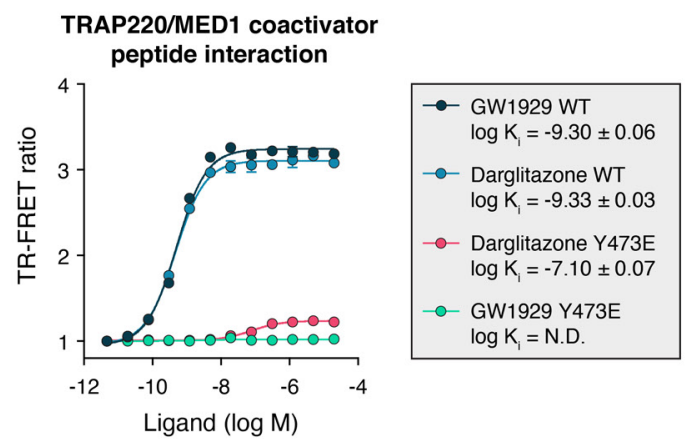

D
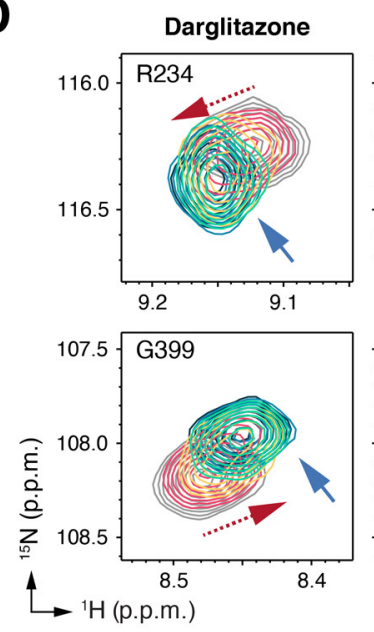
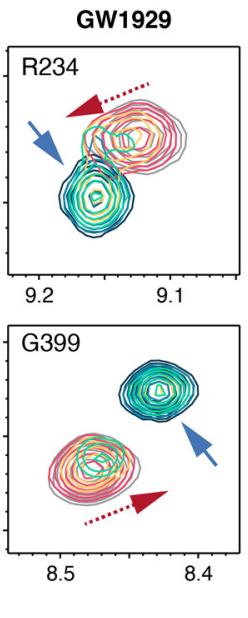

B

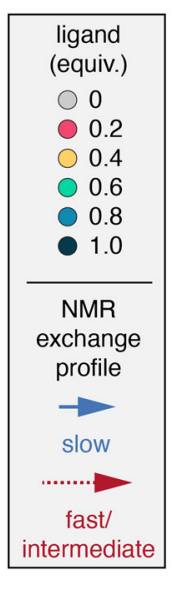

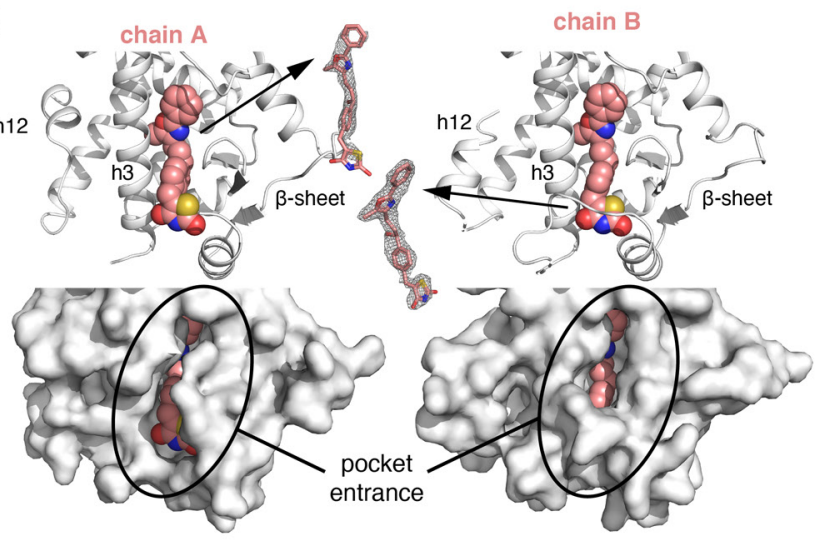

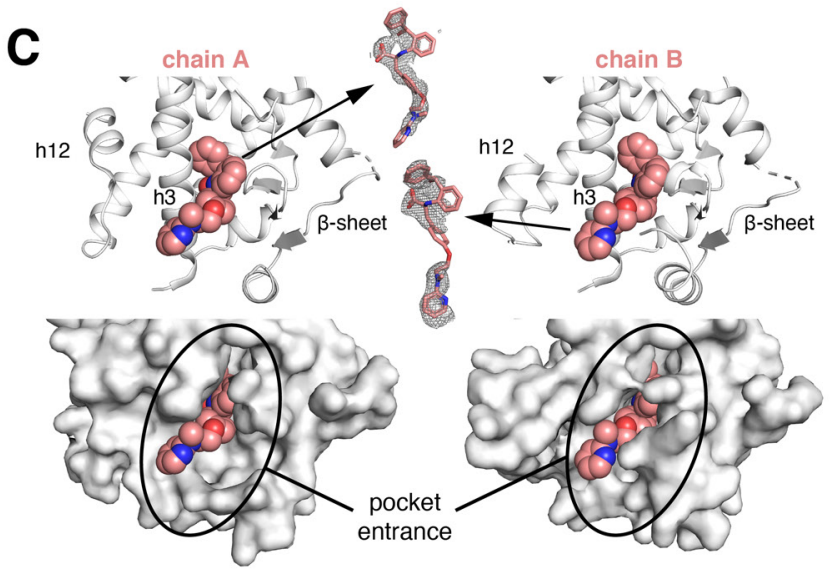

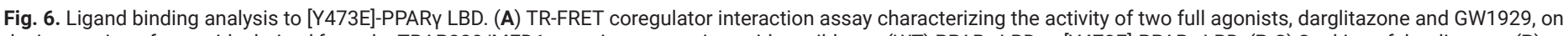

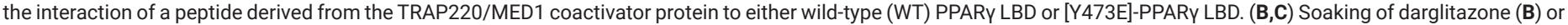

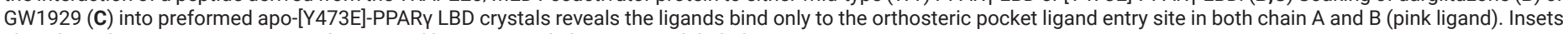
show ligand 2 Fo-Fc maps contoured at $1 \sigma$, and key structural elements are labeled.

\section{DISCUSSION}

There is evidence that the functional activity of ligand-bound NRs is associated with a shift in the dynamic LBD conformational ensemble from a ground state to an active state. For example, in the absence of ligand, the PPAR $\gamma$ LBD is conformationally dynamic, samples multiple conformation, and binding of an agonist stabilizes the LBD in an active conformation to a degree correlated with the activity of the ligand $(18,23-25)$. The association between ligand-bound NR LBD conformation and graded function is evidence for conformational selection in the mechanism of NR ligand activity $(13,15,19-22,53)$. However, these studies only address the functional mechanism of the ligand-bound state; they do not address the mechanism of ligand binding. In this study, we directly probed the mechanism of ligand binding to PPAR $\gamma$ using NMR lineshape analysis, a powerful method for studying binding equilibria at atomic resolution that can differentiate conformational selection and induced fit binding mechanisms (28).

Our NMR data show that agonists bind to the PPAR $\gamma$ orthosteric pocket via a two-state induced fit mechanism. The first step is characterized by a fast binding event, which is supported by our SPR data and likely occurs at a surface pore formed by helix 3 , the $\beta$-sheet, and the $\Omega$-loop. This is a site where ligands can bind in the non-active conformation PPAR $\gamma$ LBD crystal structures as well as our Y473E mutant crystal structures, and it is the ligand entry site suggested in unbiased coarse-grained molecular simulations of FXR (7) and targeted simulations of PPAR $\gamma$ (8). Molecular simulations of other NRs have suggested other ligand entry sites including a conserved surface in steroid receptors at the intersection of helix 3, 7, and $11(9,10)$, suggesting that certain classes of NRs may use different ligand entry sites to the orthosteric pocket.
The second slower step detected by our NMR studies is associated with a conformational change after the initial fast binding event, which is supported by our ITC heat capacity analysis. This step likely represents transition of the ligand from the initial encounter complex at the surface pore ligand entry site to the final bound conformation within the orthosteric pocket. Molecular simulation studies of ligand binding to FXR (7) and PPAR $\gamma$ (8) support this conformational change step. In the study on PPAR $\gamma$, binding of an agonist called GW0072 was described to rotate on itself during a transition from its initial binding pose to the final bound conformation. This is conceptually similar to the crystallized PPAR $\gamma$ ligand binding modes we describe here. In the structures of darglitazone bound to the pocket entry site, the TZD headgroup is solvent exposed-if this represents an initial encounter complex binding pose that is populated in solution, the TZD headgroup would need to swing around helix 3 through a rotation point at the intersection of helix 3 and 5 to migrate to the final orthosteric binding pose. In the structures of GW 1929 bound to the pocket entry site, the acid headgroup points into the pocket and if this also represents an initial encounter complex binding pose that is populated in solution it would need to flip $\sim 180^{\circ}$ during the transition into the final orthosteric binding pose. The unbiased coarse-grained simulations of obeticholic acid binding to FXR revealed a similar multi-step mechanism with the final step associated with a rearrangement of the FXR LBD and a transition of the ligand to the inner binding pose within the orthosteric pocket (7).

Our findings extend a model for the molecular mechanism of agonist binding and activation of PPAR $\gamma$ (Fig. 7). In the absence of ligand, several regions of apo-PPAR $\gamma$ LBD exchanges between multiple conformations on the microsecond-millisecond ( $\mu \mathrm{s}-\mathrm{ms})$ time scale including the ortho- 
bioRxiv preprint doi: https://doi.org/10.1101/2020.09.22.298109; this version posted September 22, 2020. The copyright holder for this preprint (which was not certified by peer review) is the author/funder, who has granted bioRxiv a license to display the preprint in perpetuity. It is made available under aCC-BY 4.0 International license.

steric ligand-binding pocket and the AF-2 helix 12 (18). One of these conformations was assumed to be the active NR LBD conformation that has been captured in most NR crystal structures. Using paramagnetic relaxation enhancement (PRE) NMR, we recently showed for apoPPAR $\gamma$ LBD that the $\mu$ s-ms time scale dynamics is caused by exchange of the AF-2 helix 12 in and out of the orthosteric ligand-binding pocket, which are associated with the transcriptionally repressive and active conformations (17). This suggests that there may be a competition between the repressive helix 12 conformation within the orthosteric pocket and the transition of the ligand from the encounter complex bound at the entry site to the final binding pose in the orthosteric pocket. It is possible that this transition pushes helix 12 out of the repressive conformation within the orthosteric pocket to a solvent-exposed active conformation, a signature of what might be considered a true induced fit binding mechanism. Alternatively, the binding mechanism could involve a mixture of induced fit binding and conformational selection where helix 12 may adopt an active-like conformation prior to the ligand transitioning to the final binding pose in the orthsoteric pocket if the time scale by which helix $12 \mathrm{ex}-$ changes out of the pocket is not rate limiting (5). Other NMR studies have similarly found that the orthosteric pocket and helix 12 in other apo-NR LBDs are dynamic on the $\mu \mathrm{s}$-ms time scale including FXR, PPAR $\alpha$, retinoid $\mathrm{X}$ receptor alpha $(\mathrm{RXR} \alpha)$, and vitamin $\mathrm{D}$ receptor (VDR) (19-21, 27). Thus, the ligand binding mechanism we describe here for PPAR $\gamma$ may occur for other NRs as well, a hypothesis that could be tested by NMR and biophysical studies as demonstrated in this study.

\section{ACKNOWLEDGEMENTS}

This work was supported by National Institutes of Health (NIH) grant R01DK124870. Use of the Stanford Synchrotron Radiation Lightsource, SLAC National Accelerator Laboratory, is supported by the U.S. Department of Energy, Office of Science, Office of Basic Energy Sciences under Contract No. DE-AC02-76SF00515. The SSRL Structural Molecular Biology Program is supported by the DOE Office of Biological and Environmental Research, and by the National Institutes of Health, National Institute of General Medical Sciences (including P41GM103393). The contents of this publication are solely the responsibility of the authors and do not necessarily represent the official views of NIDDK or NIH.

\section{AUTHOR CONTRIBUTIONS}

J.S. and D.J.K. conceived and designed the research. J.S. performed all experiments and analyzed data. D.J.K. analyzed data and supervised the research. J.S. and D.J.K. wrote the manuscript.

\section{COMPETING FINANCIAL INTERESTS}

The authors declare no competing financial interests.

\section{METHODS}

\section{Materials and reagents}

Darglitazone and GW1929 were obtained from Cayman Chemical, MRL24 was obtained from BioVision; ligands were dissolved in DMSO- $\mathrm{d}_{6}$ at 20 mM stocks. Peptides of LXXLL-containing motif from human TRAP220/ MED1 (UniProt Q15648; residues 638-656; NTKNHPMLMNLLKDN-
PAQD) with an N-terminal FITC label, a six-carbon linker (Ahx), and an amidated C-terminus for stability was synthesized by LifeTein.

\section{Protein expression and purification}

Wild-type or Y473E mutant human PPAR $\gamma$ LBD (UniProt P37231; residues 203-477, isoform 1 numbering) protein was expressed from a pET46 Ek/LIC vector (Novagen) as a Tobacco Etch Virus (TEV)-cleavable N-terminal Hexa(6x)His-tagged fusion protein in Escherichia coli BL21(DE3) cells using autoinduction ZY media (grown at $22^{\circ} \mathrm{C}$; harvested after overnight growth), or M9 minimal media supplemented with ${ }^{15} \mathrm{NH}_{4} \mathrm{Cl}$ (induced with $0.4 \mathrm{mM}$ isopropyl $\beta$-d-1-thiogalactopyranoside at O.D. $\sim 0.8$; grown at $18^{\circ} \mathrm{C}$; harvested after overnight growth). The Y473E PPAR $\gamma$ LBD mutant was generated with site directed mutagenesis using the following forward primer and the corresponding reverse primer: 5'-CTGCAGGAGATCGAAAAGGACTTGTAC-3'. Proteins were purified using Ni-NTA affinity chromatography, in some cases a second $\mathrm{Ni}$ NTA affinity chromatography step after cleavage of the $6 x$ His-tag by TEV protease (at a ratio of $1 \mathrm{mg}$ TEV protease : $50 \mathrm{mg}$ of PPAR $\gamma$ LBD), and finally gel filtration chromatography. Purified protein was concentrated to $10 \mathrm{mg} / \mathrm{mL}$ in a buffer consisting of $20 \mathrm{mM}$ potassium phosphate ( $\mathrm{pH} 7.4$ ), $50 \mathrm{mM}$ potassium chloride, $5 \mathrm{mM}$ tris(2-carboxyethyl)phosphine (TCEP), and $0.5 \mathrm{mM}$ ethylenediaminetetraacetic acid (EDTA). Purified proteins were verified by SDS-PAGE as $>95 \%$ pure. Delipidated protein was obtained by denaturation using a chloroform/methanol lipid extraction 
method and refolding using a fast dilution/dialysis procedure followed by size exclusion chromatography (54).

\section{TR-FRET assays}

The time-resolved fluorescence resonance energy transfer (TR-FRET) assays were performed in black 384-well plates (Greiner). Ligand stocks were prepared via serial dilution in DMSO and added to wells. For the TR-FRET ligand displacement assay, each well ( $23 \mu \mathrm{L}$ total volume) contained $1 \mathrm{nM}$ 6xHis-tagged PPAR $\gamma$ LBD protein, $1 \mathrm{nM}$ LanthaScreen Elite Tb-anti-HIS antibody (Thermo Fisher), and 5 nM Fluormone Pan-PPAR Green fluorescent tracer ligand (Invitrogen) in the same buffer. For the coregulator interaction assay, each well ( $23 \mu \mathrm{L}$ total volume) contained 4 nM 6xHis-tagged PPAR $\gamma$ LBD, 1 nM LanthaScreen Elite Tb-anti-HIS antibody (Thermo Fisher), and 400 nM FITC-labeled TRAP220 or NCoR peptide in a buffer consisting of $20 \mathrm{mM}$ potassium phosphate $(\mathrm{pH} 8)$, $50 \mathrm{mM}$ potassium chloride, $5 \mathrm{mM}$ TCEP, and $0.005 \%$ Tween 20. Plates were incubated at $25^{\circ} \mathrm{C}$ for $1 \mathrm{~h}$ and read using Synergy Neo plate reader (BioTek). The $\mathrm{Tb}$ donor was excited at $340 \mathrm{~nm}$, its emission was monitored at $492 \mathrm{~nm}$, and the acceptor FITC emission was measured at $520 \mathrm{~nm}$. Data were analyzed using GraphPad Prism. TR-FRET coregulator data were fit to sigmoidal dose response curve equation, and ligand displacement data were fit to the "one site - Fit Ki" binding equation to obtain $\mathrm{K}_{\mathrm{i}}$ values using the published binding affinity of Fluormone Pan-PPAR Green (2.8 nM; Invitrogen PV4894 info sheet).

\section{NMR spectroscopy}

Two dimensional (2D) $\left[{ }^{1} \mathrm{H},{ }^{15} \mathrm{~N}\right]$-transverse relaxation optimized spectroscopy (TROSY) heteronuclear single quantum coherence (HSQC) data were collected on a Bruker $700 \mathrm{MHz}$ NMR spectrometer equipped with a QCI cryoprobe at 298K using Topspin 3.0 (Bruker). Samples contained $200 \mu \mathrm{M}{ }^{15} \mathrm{~N}-\mathrm{PPAR} \gamma \mathrm{LBD}$ at increasing ligand concentrations $(0,0.2,0.4$, $0.6,0.8$, and 1.0 equivalents); a DMSO control experiment (1.0 equivalent of vehicle) showed no significant perturbations. Data were processed using NMRFx Processor (55) and analyzed using NMRViewJ and NMRFx Analyst (56). Backbone NMR chemical shift assignments for GW1929bound PPAR $\gamma$ LBD were previously reported (57).

\section{Surface plasmon resonance}

Surface plasmon resonance (SPR) measurements were performed on a Biacore X100 instrument (GE Healthcare). 6xHis-tagged PPAR $\gamma$ LBD protein was immobilized on an NTA sensor chip (GE Healthcare), which includes a reference flow cell for background subtraction, at a density not exceeding 2,000 RU using reagents supplied by NTA reagent kit (GE Healthcare). Measurements were performed in a buffer (1X HBS-P+ buffer) containing $10 \mathrm{mM}$ HEPES, $150 \mathrm{mM} \mathrm{NaCl}$ and $0.05 \%$ (v/v) Surfactant $\mathrm{P} 20$ at a flow rate of $10 \mu \mathrm{L} / \mathrm{min}$. For kinetic and affinity measurements, GW1929 was diluted in 1X HBS-P+ buffer and injected at 8 concentrations with one duplicate. The NTA sensor chip was regenerated between each GW1929 concentration measurement by stripping $\mathrm{Ni}^{2+}$ using EDTA and recharging with $\mathrm{NiCl}_{2}$.

\section{Isothermal titration calorimetry}

Isothermal titration calorimetry (ITC) experiments were carried out on a iTC200 calorimeter (MicroCal/GE/Malvern) using the iTC200 software (v 1.24.2) for instrument control and data acquisition. GW 1929 (present in the syringe at $300 \mu \mathrm{M}$ ) was diluted in a buffer consisting of $20 \mathrm{mM}$ potassium phosphate ( $\mathrm{pH} 7.4$ ), $50 \mathrm{mM}$ potassium chloride, $5 \mathrm{mM}$ TCEP, 0.5 mM EDTA, and 0.17\% DMSO. Wild-type or Y473E PPAR $\gamma$ LBD protein (present in the sample cell at $30 \mu \mathrm{M}$ ) was diluted in the same buffer. Titrations were performed with a $0.4 \mu \mathrm{L}$ pre-injection followed by nineteen $2 \mu \mathrm{L}$ injections. Mixing was carried out at five temperatures $\left(10^{\circ} \mathrm{C}, 18^{\circ} \mathrm{C}\right.$, $25^{\circ} \mathrm{C}, 30^{\circ} \mathrm{C}, 37^{\circ} \mathrm{C}$ ) for wild-type PPAR $\gamma \mathrm{LBD}$ or $25^{\circ} \mathrm{C}$ for [Y473E]-PPAR $\gamma$
LBD with reference power and rotational stirring set at $5 \mu \mathrm{cal} \mathrm{s}{ }^{-1}$ and 1200 rpm, respectively. Data analysis was performed using software packages NITPIC, SEDPHAT, and GUSSI (58-61).

\section{Crystallization, structure determination, and structural analysis}

Crystals of wild-type and Y473E PPAR $\gamma$ LBD were obtained after 3-8 days at $22^{\circ} \mathrm{C}$ by sitting-drop vapor diffusion against $50 \mu \mathrm{L}$ of well solution using 96-well format crystallization plates. The crystallization drops contained $1 \mu \mathrm{L}$ of protein/ligand sample mixed with $1 \mu \mathrm{L}$ of reservoir solution containing 0.1 M MOPS ( $\mathrm{pH} 7.6$ ) and 0.8 M sodium citrate. Crystals for the darglitazone and GW 1929-PPAR $\gamma$ LBD complexes were obtained by soaking ligands ( $1.5 \mathrm{mM}$ in reservoir solution containing $5 \% \mathrm{DMSO}$ ) into preformed apo-PPAR $\gamma$ LBD crystals for about 1 week. All crystals were flash-frozen in liquid nitrogen before data collection. Data collection for the wild-type apo-refolded and GW 1929-bound structures were collected at Berkeley Center for Structural Biology beamline 5.0.3; the apo-Y473E mutant and GW1929 or darglitazone-bound Y473E mutant structures were collected at SLAC National Accelerator Laboratory/Stanford Synchrotron Radiation Lightsource (SSRL) beamline 12-2. Data were processed, integrated, and scaled with the programs Mosflm (62) and Scala in CCP4 (63). The structure was solved by molecular replacement using the program Phaser (64) that is implemented in the PHENIX package (65) using previously published PPAR $\gamma$ LBD structure (PDB code 1PRG) (66) as the search model. The structure was refined using PHENIX with several cycles of interactive model rebuilding in Coot (67). The align command in PyMOL (Schrödinger) was used to calculate C $\alpha$ R.M.S.D. values with the number of alignment refinement cycles set to 0 .

\section{REFERENCES}

1. G. Holzer, G. V. Markov, V. Laudet, Evolution of Nuclear Receptors and Ligand Signaling: Toward a Soft Key-Lock Model? Curr. Top. Dev. Biol. 125, 1-38 (2017).

2. G. M. Santos, L. Fairall, J. W. R. Schwabe, Negative regulation by nuclear receptors: a plethora of mechanisms. Trends Endocrinol. Metab. TEM 22, 87-93 (2011).

3. D. J. Kojetin, T. P. Burris, Small molecule modulation of nuclear receptor conformational dynamics: implications for function and drug discovery. Mol. Pharmacol. 83, 1-8 (2013).

4. E. R. Weikum, X. Liu, E. A. Ortlund, The nuclear receptor superfamily: A structural perspective. Protein Sci. Publ. Protein Soc. 27, 1876-1892 (2018).

5. H.-X. Zhou, From induced fit to conformational selection: a continuum of binding mechanism controlled by the timescale of conformational transitions. Biophys. J. 98, L1517 (2010).

6. A. Fischer, M. Smieško, Ligand Pathways in Nuclear Receptors. J. Chem. Inf. Model. 59, 3100-3109 (2019).

7. P. C. T. Souza, S. Thallmair, P. Conflitti, C. Ramírez-Palacios, R. Alessandri, S. Raniolo, V. Limongelli, S. J. Marrink, Protein-ligand binding with the coarse-grained Martini model. Nat. Commun. 11, 3714 (2020).

8. S. Aci-Sèche, M. Genest, N. Garnier, Ligand entry pathways in the ligand binding domain of PPARY receptor. FEBS Lett. 585, 2599-2603 (2011).

9. K. Edman, A. Hosseini, M. K. Bjursell, A. Aagaard, L. Wissler, A. Gunnarsson, T. Kamins ki, C. Köhler, S. Bäckström, T. J. Jensen, A. Cavallin, U. Karlsson, E. Nilsson, D. Lecina, R. Takahashi, C. Grebner, S. Geschwindner, M. Lepistö, A. C. Hogner, V. Guallar, Ligand Binding Mechanism in Steroid Receptors: From Conserved Plasticity to Differential Evolutionary Constraints. Struct. Lond. Engl. 1993 23, 2280-2290 (2015).

10. C. Grebner, D. Lecina, V. Gil, J. Ulander, P. Hansson, A. Dellsen, C. Tyrchan, K. Edman, A Hogner, V. Guallar, Exploring Binding Mechanisms in Nuclear Hormone Receptors by Monte Carlo and X-ray-derived Motions. Biophys. J. 112, 1147-1156 (2017).

11. P. Huang, V. Chandra, F. Rastinejad, Structural overview of the nuclear receptor superfamily: insights into physiology and therapeutics. Annu. Rev. Physiol. 72, 247-272 (2010).

12. F. M. Sladek, What are nuclear receptor ligands? Mol. Cell. Endocrinol. 334, 3-13 (2011).

13. C. D. Okafor, J. K. Colucci, and E. A. Ortlund, Ligand-Induced Allosteric Effects Governing SR Signaling. Nucl. Recept. Res. 6 (2019).

14. F. Rastinejad, P. Huang, V. Chandra, S. Khorasanizadeh, Understanding nuclear receptor form and function using structural biology. J. Mol. Endocrinol. 51, T1-T21 (2013).

15. J. B. Bruning, A. A. Parent, G. Gil, M. Zhao, J. Nowak, M. C. Pace, C. L. Smith, P. V. Afonine, P. D. Adams, J. A. Katzenellenbogen, K. W. Nettles, Coupling of receptor conformation and ligand orientation determine graded activity. Nat. Chem. Biol. 6, 837-843 (2010).

16. J. B. Bruning, M. J. Chalmers, S. Prasad, S. A. Busby, T. M. Kamenecka, Y. He, K. W. 
bioRxiv preprint doi: https://doi.org/10.1101/2020.09.22.298109; this version posted September 22, 2020. The copyright holder for this preprint (which was not certified by peer review) is the author/funder, who has granted bioRxiv a license to display the preprint in perpetuity. It is made available under aCC-BY 4.0 International license.

Nettles, P. R. Griffin, Partial agonists activate PPARgamma using a helix 12 independent mechanism. Struct. Lond. Engl. 1993 15, 1258-1271 (2007).

17. J. Shang, S. A. Mosure, J. Zheng, R. Brust, J. Bass, A. Nichols, L. A. Solt, P. R. Griffin, D. J. Kojetin, A molecular switch regulating transcriptional repression and activation of PPARY. Nat. Commun. 11, 956 (2020).

18. B. A. Johnson, E. M. Wilson, Y. Li, D. E. Moller, R. G. Smith, G. Zhou, Ligand-induced stabilization of PPARgamma monitored by NMR spectroscopy: implications for nuclear receptor activation. J. Mol. Biol. 298, 187-194 (2000).

19. P. Cronet, J. F. Petersen, R. Folmer, N. Blomberg, K. Sjöblom, U. Karlsson, E. L. Lindstedt, K. Bamberg, Structure of the PPARalpha and -gamma ligand binding domain in complex with AZ 242; ligand selectivity and agonist activation in the PPAR family. Struct. Lond. Engl. 1993 9, 699-706 (2001).

20. J. Lu, D. P. Cistola, E. Li, Analysis of ligand binding and protein dynamics of human retinoid $X$ receptor alpha ligand-binding domain by nuclear magnetic resonance. Biochemistry 45, 1629-1639 (2006).

21. K. K. Singarapu, J. Zhu, M. Tonelli, H. Rao, F. M. Assadi-Porter, W. M. Westler, H. F. DeLuca, J. L. Markley, Ligand-specific structural changes in the vitamin D receptor in solution. Biochemistry 50, 11025-11033 (2011).

22. C. Köhler, G. Carlström, A. Gunnarsson, U. Weininger, S. Tångefjord, V. Ullah, M. Lepistö, U. Karlsson, T. Papavoine, K. Edman, M. Akke, Dynamic allosteric communication pathway directing differential activation of the glucocorticoid receptor. Sci. Adv. 6, eabb5277 (2020).

23. I. M. Chrisman, M. D. Nemetchek, I. M. S. de Vera, J. Shang, Z. Heidari, Y. Long, H. Reyes-Caballero, R. Galindo-Murillo, T. E. Cheatham, A.-L. Blayo, Y. Shin, J. Fuhrmann, P. R. Griffin, T. M. Kamenecka, D. J. Kojetin, T. S. Hughes, Defining a conformational ensemble that directs activation of PPARY. Nat. Commun. 9, 1794 (2018).

24. J. Shang, R. Brust, P. R. Griffin, T. M. Kamenecka, D. J. Kojetin, Quantitative structural assessment of graded receptor agonism. Proc. Natl. Acad. Sci. U. S. A. 116, 22179-22188 (2019).

25. T. S. Hughes, M. J. Chalmers, S. Novick, D. S. Kuruvilla, M. R. Chang, T. M. Kamenecka, M. Rance, B. A. Johnson, T. P. Burris, P. R. Griffin, D. J. Kojetin, Ligand and receptor dynamics contribute to the mechanism of graded PPARy agonism. Struct. Lond. Engl. 199320 139-150 (2012).

26. M. R. B. Batista, L. Martínez, Conformational Diversity of the Helix 12 of the Ligand Binding Domain of PPARY and Functional Implications. J. Phys. Chem. B 119, 15418-15429 (2015).

27. D. Merk, S. Sreeramulu, D. Kudlinzki, K. Saxena, V. Linhard, S. L. Gande, F. Hiller, C Lamers, E. Nilsson, A. Aagaard, L. Wissler, N. Dekker, K. Bamberg, M. Schubert-Zsilavecz, H. Schwalbe, Molecular tuning of farnesoid X receptor partial agonism. Nat. Commun. 10, 2915 (2019).

28. E. L. Kovrigin, NMR line shapes and multi-state binding equilibria. J. Biomol. NMR 53, 257-270 (2012).

29. B. R. Henke, S. G. Blanchard, M. F. Brackeen, K. K. Brown, J. E. Cobb, J. L. Collins, W. W. Harrington, M. A. Hashim, E. A. Hull-Ryde, I. Kaldor, S. A. Kliewer, D. H. Lake, L. M. Leesnitzer, J. M. Lehmann, J. M. Lenhard, L. A. Orband-Miller, J. F. Miller, R. A. Mook, S. A. Noble, W. Oliver, D. J. Parks, K. D. Plunket, J. R. Szewczyk, T. M. Willson, N-(2-Benzoylphenyl)-L-tyrosine PPARgamma agonists. 1. Discovery of a novel series of potent antihyperglycemic and antihyperlipidemic agents. J. Med. Chem. 41, 5020-5036 (1998).

30. A. Bernardes, F. A. H. Batista, M. de Oliveira Neto, A. C. M. Figueira, P. Webb, D. Saidemberg, M. S. Palma, I. Polikarpov, Low-resolution molecular models reveal the oligomeric state of the PPAR and the conformational organization of its domains in solution. PloS One 7, e31852 (2012)

31. L. M. van Marrewijk, S. W. Polyak, M. Hijnen, D. Kuruvilla, M. R. Chang, Y. Shin, T. M. Kamenecka, P. R. Griffin, J. B. Bruning, SR2067 Reveals a Unique Kinetic and Structural Signature for PPARy Partial Agonism. ACS Chem. Biol. 11, 273-283 (2016).

32. I. Kratochvil, T. Hofmann, S. Rother, R. Schlichting, R. Moretti, D. Scharnweber, V. Hintze, B. I. Escher, J. Meiler, S. Kalkhof, M. von Bergen, Mono(2-ethylhexyl) phthalate (MEHP) and mono(2-ethyl-5-oxohexyl) phthalate (MEOHP) but not di(2-ethylhexyl) phthalate (DEHP) bind productively to the peroxisome proliferator-activated receptor $y$. Rapid Commun. Mass Spectrom. RCM 33 Suppl 1, 75-85 (2019).

33. S.-S. Choi, E. S. Kim, M. Koh, S.-J. Lee, D. Lim, Y. R. Yang, H.-J. Jang, K.-A. Seo, S.-H. Min I. H. Lee, S. B. Park, P.-G. Suh, J. H. Choi, A novel non-agonist peroxisome proliferator-activated receptor Y (PPARY) ligand UHC1 blocks PPARy phosphorylation by cyclin-dependent kinase 5 (CDK5) and improves insulin sensitivity. J. Biol. Chem. 289, 26618-26629 (2014).

34. X. Xie, X. Zhou, W. Chen, L. Long, W. Li, X. Yang, S. Li, L. Wang, L312, a novel PPARY ligand with potent anti-diabetic activity by selective regulation. Biochim. Biophys. Acta $\mathbf{1 8 5 0}$, 62-72 (2015).

35. T. Waku, T. Shiraki, T. Oyama, K. Maebara, R. Nakamori, K. Morikawa, The nuclear receptor PPARY individually responds to serotonin- and fatty acid-metabolites. EMBO J.29, 3395-3407 (2010).

36. Y. Li, L. Li, J. Chen, T. Hu, J. Huang, Y. Guo, H. Jiang, X. Shen, 7-Chloroarctinone-b as a new selective PPARgamma antagonist potently blocks adipocyte differentiation. Acta Pharmacol. Sin. 30, 1351-1358 (2009).

37. J. Y. Jang, H.-J. Kim, B. W. Han, Structural Basis for the Regulation of PPARY Activity by Imatinib. Mol. Basel Switz. 24 (2019)

38. M. Vasaturo, L. Fiengo, N. De Tommasi, L. Sabatino, P. Ziccardi, V. Colantuoni, M. Bru- no, C. Cerchia, E. Novellino, A. Lupo, A. Lavecchia, F. D. Piaz, A compound-based proteomic approach discloses 15-ketoatractyligenin methyl ester as a new PPARy partial agonist with anti-proliferative ability. Sci. Rep. 7, 41273 (2017).

39. W. Lu, P. Che, Y. Zhang, H. Li, S. Zou, J. Zhu, J. Deng, X. Shen, H. Jiang, J. Li, J. Huang, HL005--a new selective PPARY antagonist specifically inhibits the proliferation of MCF-7. J. Steroid Biochem. Mol. Biol. 124, 112-120 (2011).

40. F. Ye, Z.-S. Zhang, H.-B. Luo, J.-H. Shen, K.-X. Chen, X. Shen, H.-L. Jiang, The dipeptide $\mathrm{H}$-Trp-Glu-OH shows highly antagonistic activity against PPARgamma: bioassay with molecular modeling simulation. Chembiochem Eur. J. Chem. Biol. 7, 74-82 (2006)

41. Y. Jin, Y. Han, D. B. Khadka, C. Zhao, K. Y. Lee, W.-J. Cho, Discovery of Isoquinolinoquinazolinones as a Novel Class of Potent PPARy Antagonists with Anti-adipogenic Effects. Sci. Rep. 6, 34661 (2016)

42. L. Yue, F. Ye, X. Xu, J. Shen, K. Chen, X. Shen, H. Jiang, The conserved residue Phe273(282) of PPARalpha(gamma), beyond the ligand-binding site, functions in binding affinity through solvation effect. Biochimie 87, 539-550 (2005).

43. S. Vega, $\mathrm{O}$. Abian, A. Velazquez-Campoy, On the link between conformational changes, ligand binding and heat capacity. Biochim. Biophys. Acta 1860, 868-878 (2016).

44. R. L. Frkic, J. B. Bruning, Obtaining Crystals of PPARy Ligand Binding Domain Bound to Small Molecules. Methods Mol. Biol. Clifton NJ 1966, 253-260 (2019).

45. D. Genest, N. Garnier, A. Arrault, C. Marot, L. Morin-Allory, M. Genest, Ligand-escape pathways from the ligand-binding domain of PPARgamma receptor as probed by molecular dynamics simulations. Eur. Biophys. J. EBJ 37, 369-379 (2008).

46. S. A. Mosure, J. Shang, J. Eberhardt, R. Brust, J. Zheng, P. R. Griffin, S. Forli, D. J. Kojetin, Structural Basis of Altered Potency and Efficacy Displayed by a Major in Vivo Metabolite of the Antidiabetic PPARy Drug Pioglitazone. J. Med. Chem. 62, 2008-2023 (2019).

47. C. R. Hopkins, S. V. O'neil, M. C. Laufersweiler, Y. Wang, M. Pokross, M. Mekel, A. Evdokimov, R. Walter, M. Kontoyianni, M. E. Petrey, G. Sabatakos, J. T. Roesgen, E. Richardson, T. P. Demuth, Design and synthesis of novel N-sulfonyl-2-indole carboxamides as potent PPAR-gamma binding agents with potential application to the treatment of osteoporosis. Bioorg. Med. Chem. Lett. 16, 5659-5663 (2006)

48. H. Bae, J. Y. Jang, S.-S. Choi, J.-J. Lee, H. Kim, A. Jo, K.-J. Lee, J. H. Choi, S. W. Suh, S. B. Park, Mechanistic elucidation guided by covalent inhibitors for the development of anti-diabetic PPARy ligands +Electronic supplementary information (ESI) available: Supplementary figures and tables, experimental methods, procedures for synthesis, and full characterization data of compounds. See DOI: 10.1039/c6sc01279e. Chem. Sci. 7, 5523-5529 (2016).

49. A. Laghezza, L. Piemontese, C. Cerchia, R. Montanari, D. Capelli, M. Giudici, M. Crestani, P. Tortorella, F. Peiretti, G. Pochetti, A. Lavecchia, F. Loiodice, Identification of the First PPARa/Y Dual Agonist Able To Bind to Canonical and Alternative Sites of PPARy and To Inhibit Its Cdk5-Mediated Phosphorylation. J. Med. Chem. 61, 8282-8298 (2018).

50. J. Y. Jang, M. Koh, H. Bae, D. R. An, H. N. Im, H. S. Kim, J. Y. Yoon, H.-J. Yoon, B. W. Han, S. B. Park, S. W. Suh, Structural basis for differential activities of enantiomeric PPARY agonists: Binding of S35 to the alternate site. Biochim. Biophys. Acta Proteins Proteomics 1865, 674-681 (2017).

51. Y. Li, Z. Wang, N. Furukawa, P. Escaron, J. Weiszmann, G. Lee, M. Lindstrom, J. Liu, X. Liu, H. Xu, O. Plotnikova, V. Prasad, N. Walker, R. M. Learned, J.-L. Chen, T2384, a novel antidiabetic agent with unique peroxisome proliferator-activated receptor gamma binding properties. J. Biol. Chem. 283, 9168-9176 (2008).

52. M. Einstein, T. E. Akiyama, G. A. Castriota, C. F. Wang, B. McKeever, R. T. Mosley, J. W. Becker, D. E. Moller, P. T. Meinke, H. B. Wood, J. P. Berger, The differential interactions of peroxisome proliferator-activated receptor gamma ligands with Tyr473 is a physical basis for their unique biological activities. Mol. Pharmacol. 73, 62-74 (2008).

53. J.-P. Changeux, S. Edelstein, Conformational selection or induced fit? 50 years of debate resolved. F1000 Biol. Rep. 3, 19 (2011)

54. E. H. Armstrong, D. Goswami, P. R. Griffin, N. Noy, E. A. Ortlund, Structural basis for ligand regulation of the fatty acid-binding protein 5 , peroxisome proliferator-activated receptor $\beta / \delta$ (FABP5-PPAR $\beta / \delta$ ) signaling pathway. J. Biol. Chem. 289, 14941-14954 (2014).

55. M. Norris, B. Fetler, J. Marchant, B. A. Johnson, NMRFx Processor: a cross-platform NMR data processing program. J. Biomol. NMR 65, 205-216 (2016).

56. B. A. Johnson, From Raw Data to Protein Backbone Chemical Shifts Using NMRFx Processing and NMRViewJ Analysis. Methods Mol. Biol. Clifton NJ 1688, 257-310 (2018).

57. J. Lu, M. Chen, S. E. Stanley, E. Li, Effect of heterodimer partner RXRalpha on PPARgamma activation function-2 helix in solution. Biochem. Biophys. Res. Commun. 365, 42-46 (2008).

58. J. C. D. Houtman, P. H. Brown, B. Bowden, H. Yamaguchi, E. Appella, L. E. Samelson, P. Schuck, Studying multisite binary and ternary protein interactions by global analysis of isothermal titration calorimetry data in SEDPHAT: application to adaptor protein complexes in cell signaling. Protein Sci. Publ. Protein Soc. 16, 30-42 (2007).

59. C. A. Brautigam, H. Zhao, C. Vargas, S. Keller, P. Schuck, Integration and global analysis of isothermal titration calorimetry data for studying macromolecular interactions. Nat. Protoc. $11,882-894$ (2016).

60. S. Keller, C. Vargas, H. Zhao, G. Piszczek, C. A. Brautigam, P. Schuck, High-precision isothermal titration calorimetry with automated peak-shape analysis. Anal. Chem. 84, 5066-5073 (2012)

61. H. Zhao, G. Piszczek, P. Schuck, SEDPHAT--a platform for global ITC analysis and global multi-method analysis of molecular interactions. Methods San Diego Calif 76, 137-148 
bioRxiv preprint doi: https://doi.org/10.1101/2020.09.22.298109; this version posted September 22, 2020. The copyright holder for this preprint (which was not certified by peer review) is the author/funder, who has granted bioRxiv a license to display the preprint in perpetuity. It is made available under aCC-BY 4.0 International license.

(2015).

62. T. G. G. Battye, L. Kontogiannis, O. Johnson, H. R. Powell, A. G. W. Leslie, iMOSFLM: a new graphical interface for diffraction-image processing with MOSFLM. Acta Crystallogr. $D$ Biol. Crystallogr. 67, 271-281 (2011).

63. M. D. Winn, C. C. Ballard, K. D. Cowtan, E. J. Dodson, P. Emsley, P. R. Evans, R. M. Keegan, E. B. Krissinel, A. G. W. Leslie, A. McCoy, S. J. McNicholas, G. N. Murshudov, N. S. Pannu, E. A. Potterton, H. R. Powell, R. J. Read, A. Vagin, K. S. Wilson, Overview of the CCP4 suite and current developments. Acta Crystallogr. D Biol. Crystallogr. 67, 235-242 (2011).

64. A. J. McCoy, R. W. Grosse-Kunstleve, P. D. Adams, M. D. Winn, L. C. Storoni, R. J. Read, Phaser crystallographic software. J. Appl. Crystallogr. 40, 658-674 (2007).

65. P. D. Adams, P. V. Afonine, G. Bunkóczi, V. B. Chen, N. Echols, J. J. Headd, L.-W. Hung, S. Jain, G. J. Kapral, R. W. Grosse Kunstleve, A. J. McCoy, N. W. Moriarty, R. D. Oeffner, R. J. Read, D. C. Richardson, J. S. Richardson, T. C. Terwilliger, P. H. Zwart, The Phenix software for automated determination of macromolecular structures. Methods San Diego Calif 55, 94-106 (2011).

66. R. T. Nolte, G. B. Wisely, S. Westin, J. E. Cobb, M. H. Lambert, R. Kurokawa, M. G. Rosenfeld, T. M. Willson, C. K. Glass, M. V. Milburn, Ligand binding and co-activator assembly of the peroxisome proliferator-activated receptor-gamma. Nature 395, 137-143 (1998).

67. P. Emsley, K. Cowtan, Coot: model-building tools for molecular graphics. Acta Crystallogr. D Biol. Crystallogr. 60, 2126-2132 (2004). 